\title{
Evaluating the Performance Engineering Process
}

\author{
Andreas Schmietendorf, André Scholz, Claus Rautenstrauch \\ University of Magdeburg, School of Computer Science \\ schmiete@ivs.cs.uni-magdeburg.de; \{ascholz|rauten\}@iti.cs.uni-magdeburg.de
}

\begin{abstract}
This contribution presents a model for process improvement in the area of performance engineering, which is called performance engineering maturity model. The use of this model allows the evaluation of the level of integration and application of performance engineering. It leans against the well-established capability maturity model from the software engineering institute. The model is based on a questionnaire catalog, which was transferred into a web based evaluation form. The results of this anonymous evaluation are analyzed in this contribution.
\end{abstract}

\section{Keywords}

Performance Engineering, capability maturity model, performance engineering maturity model, process maturity

\section{INTRODUCTION}

In practice, software engineering most time only considers functional specifications. But meanwhile companies pay more and more attention to non-functional requirements. Therefore, processes are adapted in order to develop high quality software and quality assurance systems are installed.

One of the most critical non-functional quality factor is the performance characteristic of a software system. Performance can be defined as the capability of a system to process a given amount of tasks in a determined time interval. Thereby, performance of software systems stands in direct relationship with the speed of accompanying business processes. This relationship appears especially important in the context of the current market 'Electronic Commerce by using internet technologies'. The performance characteristic of this kind of applications is one of the major success factors with regard to the acceptance of the user. Gartner Group evaluated this market as the most important expansion market for the next years [4]. A special attention must be paid on the right integration of customer's, subcontractor's and service provider's business processes with regard to performance aspects.

A lot of software engineering projects as well as productive systems fail because of insufficient performance characteristics. Up to now, performance characteristics are often only considered at the end of the software development process. If performance bottlenecks are only recognized at the end of the software development, extensive tuning activities, design modifications of the application or complete rejectings of entire software systems will be necessary.

That is why, a performance oriented software development method, like performance engineering (PE), should be integrated within the engineering process [10]. PE considers the response time as a design target throughout the whole software development process. Response time targets and analyses of the respective design structures are continuously compared. In early stages response time metrics can be quantified using estimation formulas, analytical models, simulation models and prototypes. Deviations lead to an immediate change in the software design. Thus, PE guarantees an adequate response time behavior of the productive system. PE of software systems needs an entire approach, considering the complete software development process. For this purpose, practical models of integration are already available [8].

The efficiency of the PE application depends decisively on the maturity of the PE integration and application. The higher the integration of PE processes and methods, the lower the PE costs and the performance-entailed development risks. The need for an evaluation technique of the PE integration and application was already pointed out at the "First International Workshop on Software and Performance in 1998" as well in a process group which was formed at this workshop. For that reason, we now propose a Performance Engineering Maturity Model (PEMM), which leans against the capability maturity model (CMM) to determine the grade of maturity of the PE process within the software development.

After an introduction of the basic framework of the CMM, the PEMM and it's practical application is explained. In addition, it is shown how the model was transferred into a web based evaluation form and evaluation results are discussed.

\section{THE CAPABILITY MATURITY MODEL}

The quality of software systems depends decisively on the quality of the corresponding software engineering processes. That is why, a software buyer is interested in getting to know the grade of maturity of the vendors software engineering process to draw conclusions on the software system's quality. 
The Software Engineering Institute (SEI) of Carnegie Mellon University developed a framework for evaluating the maturity of a company's software engineering process in 1987 by order of the US Department of Defense. This framework, which is known as the capability maturity model (CMM), distinguishes five different maturity levels. With the help of an evaluation catalog, the maturity of a company's software engineering process can be assigned to one of these levels. The levels are based on each other, which means that if an engineering process fulfills the requirements of a level, it also fulfills all requirements of all levels below. With an increase of the CMM level the development risk can be reduced and the productivity of development as well as the quality of the product can be increased. The individual levels and evaluation catalog can be borrowed from the relevant literature [1][2].

The CMM focuses on the software engineering process only. Additional accompaniment concepts of software engineering, like performance engineering, are hard to consider within this model. Among others the SEI also recognized the need of linking the basic CMM with performance engineering processes on some way [6]. In principle, there are two possibilities for considering performance engineering processes. On the one side the CMM could be extended or on the other side a new model could be created. We propose to create a new maturity model for performance engineering, because some companies still don't use performance engineering concepts, because they even develop performance uncritical systems.

\section{THE PERFORMANCE ENGINEERING MATURITY MODEL}

It is the aim of the PEMM to evaluate PE processes as well as the process integration [9]. The proposed evaluation model can be used for evaluation as well as for developing processes further. Furthermore, the PEMM level can become a selection criteria for choosing a software system provider for critical or semi-critical products. Thereby, a PEMM level states to what extent a concrete process is in the position to carry out a performance oriented software development. Thus, a system provider is in the position to stand out against the market. The model refers to classical business information systems (BIS) like financial application systems. Typically, BIS have the following properties [7]:

- High level of integration: Data and functions of different BIS are used in a cross-application manner.

- $\quad$ "Flat and broad" application structure: Most parts of BIS are data inputs and outputs implemented with forms and reports. Only a relatively small portion of functionality realizes complex and sophisticated algorithms.

- Rapidly changing number of users: Especially in BTC internet application the number of users might change rapidly in an unforeseeable manner.

The inclusion of special systems with a real time behavior is not recommended at this time, because the development of such kinds of systems is based on very specific engineering processes and methods.

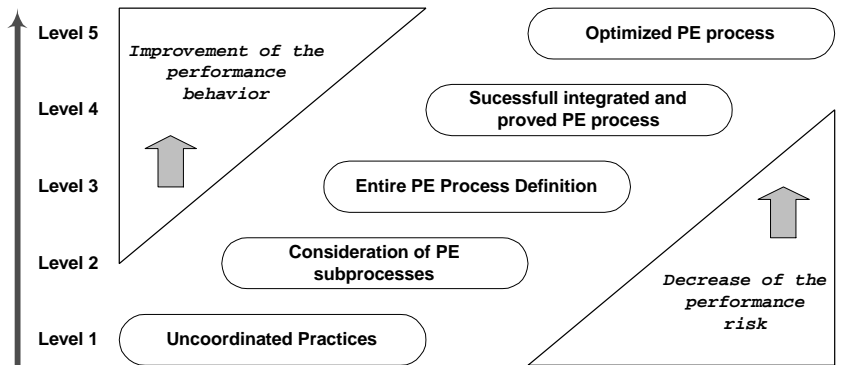

Figure 1. Maturity Levels of Performance Engineering Processes

In the following, every individual level of the PEMM (see Figure 1) is described by its most important characteristics in three sections. First, a description determines the general contents of the level. Similar to the CMM, PEMM key criteria, which are the elementary basis of each level, were defined for every maturity level. The key criteria are inherited upwards from level to level. Several aspects are assigned to every key criteria, which show which tasks have to be done for the fulfillment of the key criteria. Leaning against the Goal Question Metric Method (GQM) wise questions and metrics need to be derived from these aspects. Suitable questions have to be selected and then necessary ordinal measures (at present only 'Yes' or 'No') need to be determined for a quantified answer of these questions [3]. In this contribution, selected questions of the perspectives organization, project management, process management and technology are listed in a questionnaire catalog. However, by considering all facets of the aspects the whole questionnaire catalog would be much more complex. Because of the respective scope, the presentation of the whole catalog is not possible in this contribution.

Similar to the CMM, all levels are based on each other. A respective level implies the description and process maturity of all subordinate levels.

\subsection{PEMM Level 1 - Uncoordinated Practices}

(a) Description:

- The application of PE depends on the personal engagement of individual developers.

- The organizational structure does not support the PE process explicitly.

- Accordingly, individual methods are only used unstructured.

(b) Key Criteria: do not exist

(c) Examples for a Catalogue of Questions:

PEMM Level 1 is the initial stage of all processes. Therefore, it is not useful to define questions to determine this level.

\subsection{PEMM Level 2 - Consideration of PE Subprocesses}

(a) Description:

- Parts of the whole PE process are already considered.

- Individual PE service provider exist. 
- However, a complete process description is not yet available.

(b) Key Criteria:

- Performance Requirement Management: Performance characteristics of essential system functions are defined, which are required from the customer.

- Performance Tracking: The performance characteristics are verified throughout the whole software life cycle.

- Personal Identification: All engineers, which are involved in the development and in maintaining the software, are obliged to the quality factor performance.

(c) Examples for a Questionnaire:

Table 1. Level 2 - Examples of Questions

\begin{tabular}{|c|c|c|c|}
\hline Perspective & Questions & yes & no \\
\hline Organization & $\begin{array}{l}\text { - Is there a fundamental } \\
\text { management-agreement, that } \\
\text { performance should be } \\
\text { considered within the } \\
\text { development process? } \\
\text { - Is there a performance-related } \\
\text { communication channel? }\end{array}$ & & \\
\hline $\begin{array}{l}\text { Project } \\
\text { Management }\end{array}$ & $\begin{array}{l}\text { Are there enough resources } \\
\text { (personnel, infrastructure) to do } \\
\text { PE? } \\
\text { Do the staff have the necessary } \\
\text { skills to do PE? } \\
\text { Does the project manager know } \\
\text { elementary concepts of PE? } \\
\text { - Are performance-related tasks } \\
\text { delegated within the project? }\end{array}$ & & \\
\hline $\begin{array}{l}\text { Process } \\
\text { Management }\end{array}$ & $\begin{array}{l}\text { - Are single PE procedures } \\
\text { completely defined in written? } \\
\text { - Is a PE plan for each project } \\
\text { created? }\end{array}$ & & \\
\hline Technology & $\begin{array}{l}\text { - Are single tools used for PE } \\
\text { tasks? } \\
\text { - Are there already performance } \\
\text { experiences with technologies in } \\
\text { use? }\end{array}$ & & \\
\hline
\end{tabular}

\subsection{PEMM Level 3 - Entire PE Process Definition}

(a) Description:

- The PE process is considered within the entire software development process. All available PE methods and tools are used comprehensively with regard to the existing performance risk.

- Performance-relevant product and resource metrics are selected and standardized within the company. These metrics and their quantifications are stored and managed in appropriate database systems to guarantee a continuous reflux of experiences.

- The performance requirements of customer, which are defined in the system analyze phase, are used as success criteria at the final inspection test. Furthermore, they are arranged in service level agreements (SLA) with the provider of the software system.

- In addition, an initial organizational structure for the entire PE process is defined and introduced step by step in level 3.

\section{(b) Key Criteria:}

- Definition of PE Processes: There is an entire definition of all processes, which are necessary for PE. Different levels of abstraction have been considered.

- Performance Problem Prevention: Performance related problems as well as PE related costs are recognized very early.

- Performance Goal Management: Engineering tasks are focussed on performance goals, having an equal position as functional requirements.

- Performance Engineering Management: PE tasks are assigned to organizational structures. A management coordinates the whole process.

(c) Examples for a Questionnaire:

Table 2. Level 3 - Examples of Questions

\begin{tabular}{|c|c|c|c|}
\hline Perspective & Questions & yes & no \\
\hline Organization & $\begin{array}{l}\text { - Is there an instance, which is } \\
\text { responsible for improving and } \\
\text { adapting the PE process? } \\
\text { - Is the training of project } \\
\text { members in PE methods fixed by } \\
\text { an organizational instance? } \\
\text { Is there an independent instance, } \\
\text { which controls the } \\
\text { correspondence of performance } \\
\text { analyses and determined } \\
\text { standards? }\end{array}$ & & \\
\hline \begin{tabular}{|l|} 
Project \\
Management
\end{tabular} & 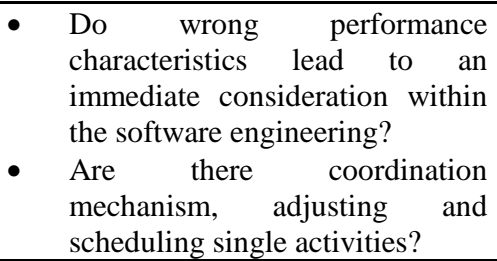 & & \\
\hline \begin{tabular}{|l} 
Process \\
Management
\end{tabular} & $\begin{array}{l}\text { - Is the whole PE process defined } \\
\text { and documented? } \\
\text { Is the integrated PE process the } \\
\text { standard process within the } \\
\text { software development? }\end{array}$ & & \\
\hline Technology & $\begin{array}{l}\text { - Is there an extensive tool support } \\
\text { for all PE methods within the } \\
\text { whole life cycle? } \\
\text { Is there a policy to use } \\
\text { standardized PE tools only? }\end{array}$ & & \\
\hline
\end{tabular}




\subsection{PEMM Level 4 - Successfully integrated and approved PE Process}

(a) Description:

- The PE tasks are a firm part of the software development. Thus, they are integrated in respective process models. Process, product and resource metrics, which are introduced in level 3, lead to extensive empirical experiences.

- All employees of the software developer and the service provider, which are involved in PE processes, have access to performance relevant metrics and experience data under the consideration of different security and view properties.

- Metrics are used for heuristics regarding the estimations of characteristics (rules of thumb), for performance models and for statistical evaluations. Furthermore, it should be possible to estimate the costs of PE.

- By the gradual increase of experience and a decrease of performance problems while implementing software systems, the surplus value of $\mathrm{PE}$ can be understood directly.

- Domain specific instances of PE are defined, e.g., for software systems, graphical tools and technical applications.

- The organizational structure develops itself further in accordance with the experiences.

\section{(b) Key Criteria:}

- Coordination of the Reflux Circle: Information flows are established between the developer and the service provider to exchange performance-relevant experiences and metrics. This reflux circle is supported on this level by repositories or metric databases.

- Metrics based PE Controlling: The surplus value of PE can be proved on the basis of saved costs.

- Performance Transparency: All used components in different layers of the software system have a sufficient description of their performance characteristics and resource consumption.

- Quality Control: The product to develop as well as all necessary components are subject to a continuos quality control. Thus, customer requirements with regard to performance can be fulfilled.

(c) Examples for a Questionnaire:

Table 3. Level 4 - Examples of Questions

\begin{tabular}{|l|l|l|l|}
\hline Perspective & Questions & yes & no \\
\hline Organization & $\begin{array}{l}\text { Are organizational structures } \\
\text { assigned to the comprehensive } \\
\text { PE process? }\end{array}$ & & \\
\hline $\begin{array}{l}\text { Project } \\
\text { Management }\end{array}$ & $\begin{array}{l}\text { Is there a cost-benefit analysis to } \\
\text { determine the surplus value of } \\
\text { PE? }\end{array}$ & & \\
\hline $\begin{array}{l}\text { Process } \\
\text { Management }\end{array}$ & $\begin{array}{l}\text { Can the PE process immediately } \\
\text { be adapted to new technologies } \\
\text { and new fields of application? }\end{array}$ & & \\
\hline
\end{tabular}

\begin{tabular}{|l|ll|l|l|}
\hline & $\begin{array}{l}\text { Are metrics used to compare and } \\
\text { evaluate performance } \\
\text { characteristics? }\end{array}$ & & & \\
\hline Technology & $\bullet \begin{array}{l}\text { Does the technology } \\
\text { infrastructure support the rapid } \\
\text { customization of the process? } \\
\text { Are performance metrics stored } \\
\text { in a database, which is available } \\
\text { within the whole development } \\
\text { and maintenance process? }\end{array}$ & $\mid$ & $\mid$ \\
\hline
\end{tabular}

\subsection{PEMM Level 5 - Optimized PE Process}

(a) Description:

- The maximum degree of process maturity is achieved.

- PE can be applied to all fields of application.

- PE can also absorb technological modifications within the software development like the use of a new middleware.

\section{(b) Key Criteria:}

- Innovation Management: The PE process is adaptable. Experiences from new application domains as well as new research results with regard to methods and tools flow continuously in the optimization of the process. The process can be adapted to new requirements. User and customer requirements in still unknown domains and technologies can be realized with determined performance characteristics.

\section{(c) Examples for a Questionnaire:}

Table 4. Level 5 - Examples of Questions

\begin{tabular}{|l|l|l|l|l|}
\hline Perspective & Questions & yes & no \\
\hline Organization & $\begin{array}{l}\text { Is there a continuous PE } \\
\text { improvement process system? }\end{array}$ & & \\
\hline $\begin{array}{l}\text { Project } \\
\text { Management }\end{array}$ & $\begin{array}{l}\text { Are new and promising methods } \\
\text { automatically tested and } \\
\text { integrated? }\end{array}$ & & \\
\hline $\begin{array}{l}\text { Process } \\
\text { Management }\end{array}$ & $\begin{array}{l}\text { Do improved engineering } \\
\text { techniques lead to a revision of } \\
\text { the software engineering } \\
\text { process? }\end{array}$ & & & \\
\hline Technology & $\begin{array}{l}\text { Are there any tools which can be } \\
\text { used in all kinds of PE } \\
\text { applications? }\end{array}$ & & \\
\hline
\end{tabular}

\section{PRACTICAL ASPECTS OF APPLICATION}

\subsection{The Maturity Level - A strategic Target}

For a practical application of the PEMM, it is useful to restrict the initial application of the model to a manageable time frame. The model, which is shown in Figure 2, only consistent of the core of the evaluation model with four levels. Level four should be achieved in five years. From our experience this is a typical time frame for a strategic plan, which also can be presented to the management. Respectively, the temporal sequence when which 
step is reached can be understood as a master plan with corresponding mile stones.

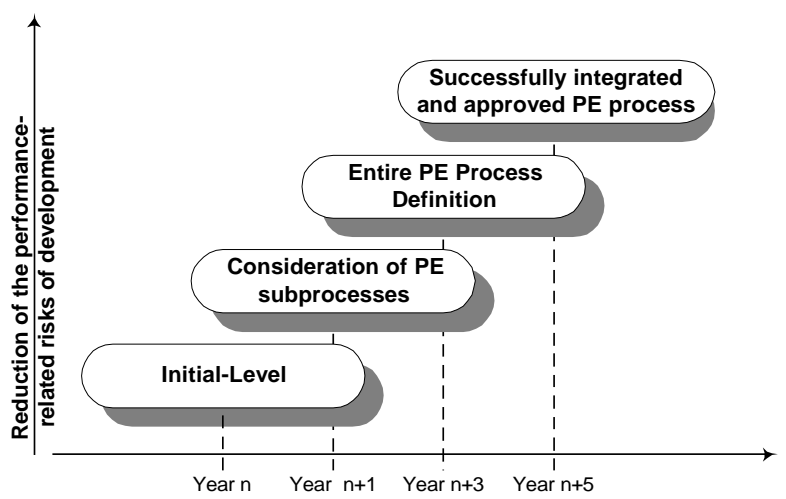

Figure 2. Introducing the Performance Engineering Maturity Model

Not only statements of the temporal horizon of the achievement of a maturity level, but also cost based statements are necessary for the introduction of the evaluation model:

ROI „,Return on Investment": This critical measure is the decision basis for the management of a respective company. It indicates them, if PE concepts should be initiated or improved.

Infrastructure based Costs: These costs comprise the costs for the creation and maintaining of the measuring and modeling instruments, e.g., the creation of a benchmarking laboratory or the implementation of databases for storing performance metrics.

Personnel Costs: The complex tasks of PE require highspecialized employees. Costs are induced by continuos training as well as by project tasks.

Performance based Development Risk: The performance based development risk should reduce in the same degree as the PE maturity level increases.

\subsection{Cooperative Exchange of Performance related Experiences}

Performance engineering relates software development and maintaining. Often two different companies are involved in these both phases, working independently together. The information flow between maintaining and development, which is necessary for performance engineering, should be regulated within a contract. Thus, the operator of the IT system is charged with costs for providing this information. An intercompany initiative, collecting respective data and providing them to all participants, could be an alternative. This kind of experience database was already tested in the field of expense estimation. But still, only a loose cycle can be set up, so that experiences flow back late to the development.

In our point of view, companies, unifying the development and maintaining of software systems, are in a better position for realizing a successful performance engineering. The problem addressed is not covered by the PEMM explicitly in this first version. But it should be considered within the practical application.

\subsection{The Evaluation Process}

Obviously, expenditures for determining the maturity level should be minimized. This can be ensured by a tool based process evaluation or by an integration of the evaluation process within the evaluation process of the CMM, if the organization is intending to determine its CMM level, too. By that, questionnaires should be designed in a way, that organizational units are only polled once.

The polling itself should be processed in a predefined and standardized procedure. It can be divided into the following phases, which are based on each other:

\section{- Preparation:}

- $\quad$ Ordered by the management

- Collection of information

- $\quad$ Training

- $\quad$ Enabling trust for the PEMM

\section{- Realization:}

- $\quad$ Polling different groups

- Evaluation

- Explication of potentials for improvement

- $\quad$ Discussing the results

- Reworking:

- Description of the present and rated situation

- Description of the strengths weaknesses profile on different topics, e.g., phase or technology based

\section{WEB BASED EVALUATION FORM}

The questionnaire was transferred into a web based evaluation form (see Figure 3). The form is provided on the web page: http://www-wi.cs.uni-magdeburg.de/ ascholz/PEMM. Beside the evaluation questions, basic questions concerning the classification of the company were integrated into the form. Thus, the kind of business, the sales volume and the number of software projects a year could cluster evaluations. Furthermore, the catalog includes questions to get to know whether the companies still have introduced the CMM and subscribed to the ISO 9000 standard. In total 34 questions have to be answered including a commentary field. 


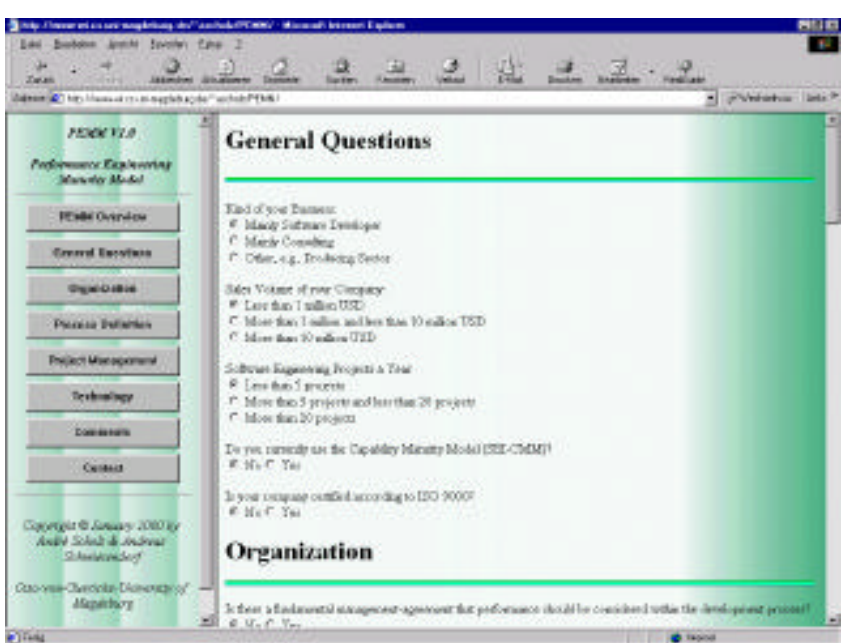

Figure 3. The Evaluation Form

The input is forwarded to a CGI script. The script stores the results in a relational database, calculates the results and creates a user feedback page.

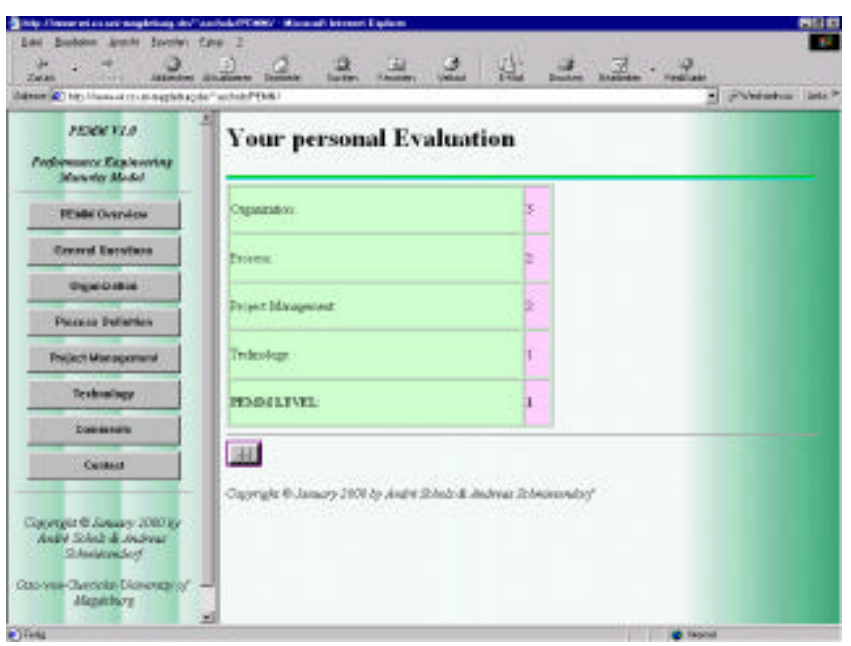

Figure 4. Evaluation Results

With the help of the answers, the PEMM level is calculated. To reach a specific level, all questions of the perspectives organization, process management, project management and technology, which are assigned to that level, have to be answered with "Yes".

Furthermore, to allow a deeper analysis of the results, the maturity levels of these individual perspectives are also calculated (see Figure 4). With it, the evaluation page provides five maturity levels in total.

\section{ANAL YZING THE RESULTS}

Up to now, 26 anonymous evaluations were performed from January to March 2000. Beside the aspects that not all potential companies were reached and were willing to provide the necessary information, the amount of companies interested in doing performance engineering is also limited to a small circle. Although the number of records is currently too low for intensive statistical evaluations, basic statements can be made.
All evaluated companies are still on PEMM level one. Most companies either still haven't considered performance engineering tasks within the software development or still using methods and models unstructured. For that reason, it is useful to analyze the results of the single perspectives (see Figure 5 and Figure 6). The maturity of the organization, process, project management and technology of most companies can be assigned to the initial level one. But some companies developed some of these perspectives further.

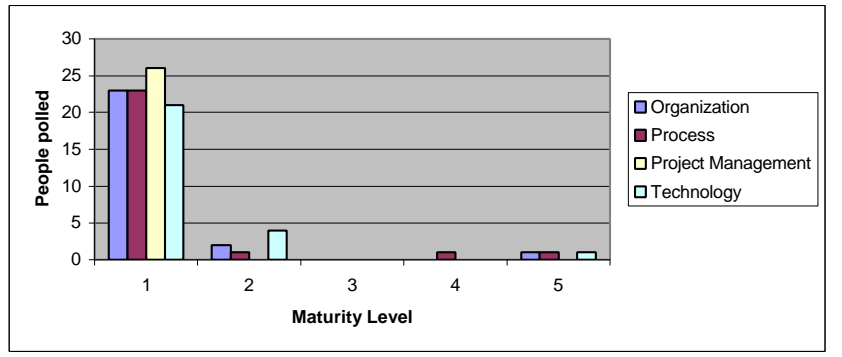

Figure 5. Distribution of the PEMM Level

In detail, some of them could reach the maturity level two and some of them reach level five already. It is from special interest to get to know which companies are the pioneers in developing their performance engineering processes.

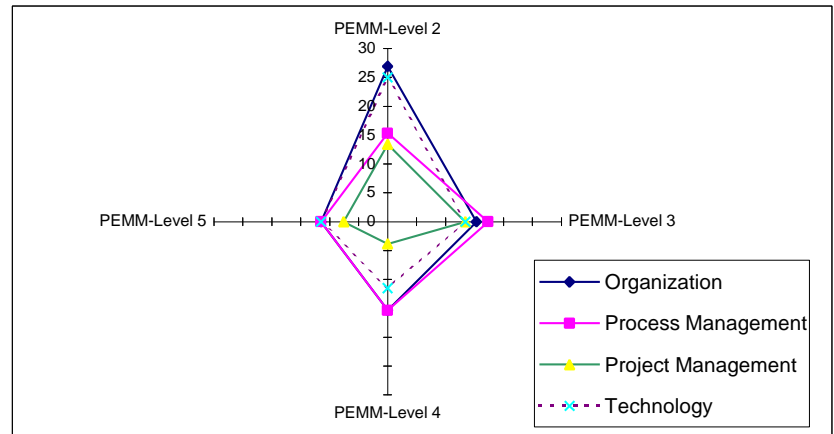

Figure 6. Kivat Diagram of the Maturity Distribution (in \%)

That is why, the data was analyzed with regard to the basic classification of the companies (see Table 5). The development steps were divided into an initial and a matured category, which give a more clustered view on the data. The initial category includes the maturity level two and three whereas the matured category includes maturity level four and five.

It can be seen that in opposite to consulting companies, developing companies show partially initial developments of their performance engineering technology as well as partly matured performance engineering process management. The same development tendencies could be realized at companies having a sales volume of more than 10 million Euro / US \$ a year.

Furthermore, data show that companies managing less than five software engineering projects a year have a partially developed initial performance engineering technology and organization. Maybe this kind of companies is focussed on developing a small amount of high quality software. 
Table 5. Further Influences and Relationships

\begin{tabular}{|c|c|c|c|c|c|c|c|c|c|}
\hline & \multicolumn{2}{|c|}{ Organization } & \multicolumn{2}{|c|}{ Process } & \multicolumn{2}{|c|}{ Project Management } & \multicolumn{2}{|c|}{ Technology } \\
\hline & & \begin{tabular}{|l|} 
initial \\
\end{tabular} & matured & initial & matured & initial & matured & \begin{tabular}{|l|} 
initial \\
\end{tabular} & matured \\
\hline$\overline{~ K i n d ~}$ & Development & & & & partial & & & partial & \\
\hline of & Consulting & & & & & & & & \\
\hline Business & Other & & & & & & & & \\
\hline \multirow[t]{2}{*}{ Sales } & $<1$ Mill. & & & & & & & & \\
\hline & > 10 Mill. & & & & partial & & & partial & \\
\hline Number & $<5$ & partial & & & & & & partial & \\
\hline of & $>5$ and $<20$ & & & & & & & & \\
\hline Projects & $>20$ & & & & & & & & \\
\hline \multirow[t]{2}{*}{ CMM } & Not subscribed & & & & & & & partial & \\
\hline & subsribed & & & & & & & & \\
\hline \multirow[t]{2}{*}{ ISO 9000} & Not subscribed & partial & & & & & & partial & \\
\hline & subsribed & & & partial & & & & & \\
\hline
\end{tabular}

Further on, it was interesting getting to know if companies using the CMM or subscribing to the ISO 9000 standard can be assigned to a higher maturity level. Data show that such a relationship could not be determined. It can be concluded that performance engineering is still not be focussed in the course of the introduction of the CMM and ISO standards.

The study has shown that all companies have to be rated with the PEMM level one. Some of them show further developments in the perspectives organization, process management and technology. The project management is the least considered.

\section{CONCLUSIONS AND OUTLOOK}

We propose a performance engineering maturity model for evaluating the application and integration of PE processes. Thus, the IT management has an instrument for a continuos comparison and improving of these specific processes. The model supplies systematics and guidelines for a process improvement and identifies existing weaknesses. These advantages become more important when it becomes clear that processes have a higher potential for improvement with regard to the whole development task than methods and tools.

For that reason we have the vision that the PEMM can reach a comparable field of application as the CMM already has. IT software system projects with strict performance requirements, especially electronic commerce applications, software systems within the telecommunication or within military applications, are now able to consider the PEMM level within a contract. With it some developing companies will be not longer in the position to take part on invitations to bid, if they don't improve their performance engineering processes. This assures the customer that companies, which come in range, develop a solution with the necessary performance requirements at a given duration of time and a fixed price.

But unfortunately some aspects still remain problematic while using the PEMM. The structure and the extension of the questionnaires are very sensitive. Empirical evaluations, if the PEMM levels are sufficiently refined by the questionnaires despite the binary set of answers, are still missing up to now.

\section{REFERENCES}

[1] Balzert, H.: Lehrbuch der Software-Technik. SoftwareManagement. Software-Qualitäts-sicherung. nehmensmodellierung, Heidelberg, Berlin, 1998.
[2] Chrissis, M.; Curtis, B.; Paulk, M.: Capability Maturity Model for Software, Version 1.1, Software Engineering Institute, Technical Report-24, Feb. 1993.

[3] Dumke, R.; Foltin, E.; Koeppe R.; Winkler, A.: Softwarequalität durch Meßtools, Vieweg-Verlag, Wiesbaden 1996

[4] GartnerGroup: Tagungsband, Symposium/ITexpo99, Cannes, Frankreich, Nov. 1999

[5] IEEE Standard for a Software Quality Metrics Methodology, IEEE Std. 1061-1992, New York, 1993

[6] Klein, M.: State of the Practice Report. Problems in the Practice of Performance Engineering, Technical Report, No. SEI-95-TR-020, Software Engineering Institute, Pittsburgh.

[7] Rautenstrauch, C.: Effiziente Gestaltung von Arbeitsplatzsystemen, Bonn et al., 1997.

[8] Rautenstrauch, C.; Scholz, A.: Vom Performance Tuning zum Software Performance Engineering am Beispiel datenbankbasierter Anwendungssysteme, in: Informatik Spektrum, Vol. 22, No. 4, 1999.

[9] Scholz, A.; Schmietendorf, A.: A risk-driven Performance Engineering Process Approach and its Evaluation with a Performance Engineering Maturity Model, in: Proceedings of the 15th Annual UK Performance Engineering Workshop, Bristol, UK, July 22-23, 1999.

[10] Scholz, A.; Schmietendorf, A.: $\mathrm{Zu}$ den Aufgaben und Inhalten des Performance Engineerings, in: HMD - Praxis der Wirtschaftsinformatik, Vol. 37, No. 213, June 2000.

Permission to make digital or hard copies of part or all of this work or personal or classroom use is granted without fee provided that copies are not made or distributed for profit or commercial advantage and that copies bear this notice and the full citation on the first page. To copy otherwise, to republish, to post on servers, or to redistribute to lists, requires prior specific permission and/or a fee.

WOSP 2000, Ontario, Canada

(C) ACM 2000 1-58113-195-X/00/09 ...\$5.00 